\title{
Pratylenchus coffeae EM CAFEEIROS: EFEITO DE DENSIDADES POPULACIONAIS DO NEMATÓIDE E TESTES COM GENÓTIPOS
}

\author{
MELISSA DALL'OGLIO TOMAZINI
}

Dissertação apresentada à Escola Superior de Agricultura "Luiz de Queiroz", Universidade de São Paulo, para obtenção do título de Mestre em Ciências, Área de Concentração: Entomologia.

P I R A C I C A B A

Estado de São Paulo - Brasil

Dezembro - 2003 


\title{
Pratylenchus coffeae EM CAFEEIROS: EFEITO DE DENSIDADES POPULACIONAIS DO NEMATÓIDE E TESTES COM GENÓTIPOS
}

\author{
MELISSA DALL'OGLIO TOMAZINI \\ Bióloga
}

Orientador: Prof. Dr. LUIZ CARLOS C. B. FERRAZ

Dissertação apresentada à Escola Superior de Agricultura "Luiz de Queiroz", Universidade de São Paulo, para obtenção do título de Mestre em Ciências, Área de Concentração: Entomologia

P IR A C I C A B A

Estado de São Paulo - Brasil

Dezembro - 2003 
Dados Internacionais de Catalogação na Publicação (CIP) DIVISÃO DE BIBLIOTECA E DOCUMENTAÇÃO - ESALQ/ USP

\author{
Tomazini, Melissa Dall'Oglio \\ Pratylenchus coffeae em cafeeiros: Efeito de densidades populacionais do nematóide e \\ testes com genótipos / Melissa Dall'Oglio Tomazini. - - Piracicaba, 2003. \\ 41 p. : il. \\ Dissertação (mestrado) - - Escola Superior de Agricultura Luiz de Queiroz, 2003. \\ Bibliografia. \\ 1. Café 2. Desenvolvimento vegetal 3. Genótipós 4. Linhagens vegetais 5. \\ de planta 6 . Resistência genética vegetal 7 . Variação genética em plantas I. Título \\ Nematóide parasi \\ CDD 633.73
}

"Permitida a cópia total ou parcial deste documento, desde que citada a fonte - $\mathrm{O}$ autor" 
Aos meus pais, Mauro e Celina, pelo enorme incentivo;

A meus familiares, Tata, Henrique, Raíssa e Rafaela;

A Fause Abdo Maluf, pela paciência,

Com amor

DEDICO

A minha avó Cinira Augustini Dal'Oglio

Com carinho

OFEREÇO 
Em memória da minha avó Maria Verginasi Tomazini,

com carinho

\section{DEDICO}


"A mais bela coragem é a confiança que devemos ter na capacidade do nosso esforço”.

(Rui Barbosa) 


\section{AGRADECIMENTOS}

À CAPES pelo suporte financeiro, através da bolsa de Mestrado.

Agradeço ao Prof. Dr. Luiz Carlos Camargo Barbosa Ferraz pela valiosa orientação, estímulo e profissionalis mo.

Agradeço especialmente ao Prof. Dr. Mário Massayuki Inomoto pelos ensinamentos, confiança e compreensão.

Ao meu padrinho da Nematologia, Dr. Guilherme Lafourcade Asmus, pesquisador da Embrapa Agropecuária Oeste, em Dourados, MS.

Aos pesquisadores Dr. Wallace Gonçalves, do Instituto Agronômico de Campinas, Cláudio Marcelo G. de Oliveira e Roberto K. Kubo, do Instituto Biológico de Campinas pela confiança.

Aos Professores do Departamento de Entomologia, Fitopatologia e Zoologia Agrícola da ESALQ/USP pelos ensinamentos, especialmente ao "Mestre" Prof. Dr. Ailton Rocha Monteiro.

Aos amigos do Laboratório de Nematologia, Andressa, Kércya, Daniel e muitos outros que tanto alegraram nosso dia-a-dia. 
Especialmente as amigas Sônia Regina Antedomênico e Rosangela Aparecida Silva pela imensa amizade, carinho, ensinamento e risos que tornaram meus dias de trabalho mais alegres.

Aos amigos e funcionários José Luiz F. Piedade e Vera L.Durrer F. de Aruda pela incessante ajuda.

Aos meus amigos de curso de graduação Mariana, Neto, Erik, José Antônio, Renato, Glauce, Daniela, Alysson: biólogos na profissão e na alma.

Aos meus amigos pós-graduandos Stella, Marcelo, Melissa, Gustavo, Edmilson e todos que passaram por essa fase juntos.

As amigas Melissa Faion e Márcia M. A. de Souza pela animada moradia.

E a todos aqueles que por esquecimento não citei, mas que de alguma forma também contribuíram em mais esta etapa de minha vida, agradeço. 


\section{SUMÁRIO}

Página

LISTA DE FIGURAS...................................................................

LISTA DE TABELAS ............................................................... xi

RESUMO........................................................................... xii

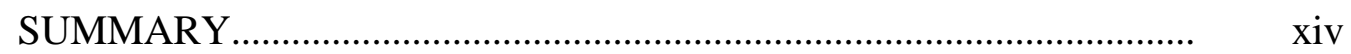

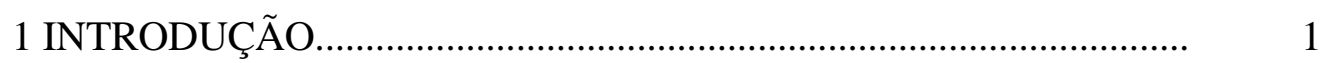

2 REVISÃO DE LITERATURA.......................................................... 4

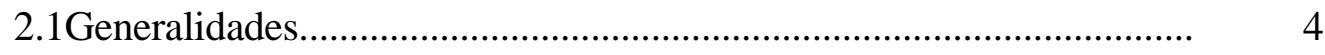

2.2 Nematóides do cafeeiro................................................................. 6

2.3 Importância dos nematóides das lesões no Brasil.................................. 7

3 MATERIAL E MÉTODOS............................................................ 12

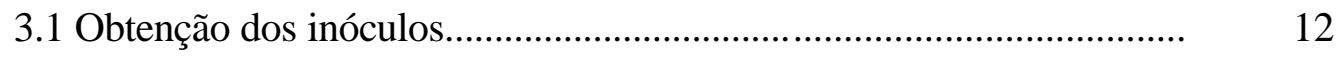

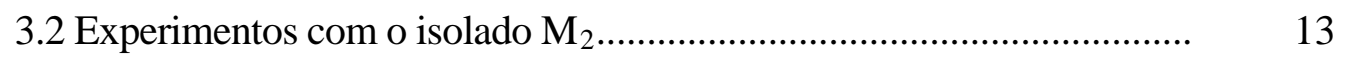

3.2.1 Obtenção das plântulas de cafeeiro 'Catuaí Vermelho' ...................... 13

3.2.2 Experimento 1. Efeito do isolado $\mathrm{M}_{2}$ no desenvolvimento de plântulas de cafeeiro 'Catuaí Vermelho' com dois pares de folhas. 
3.2.3 Experimento 2. Efeito do isolado $\mathrm{M}_{2}$ no desenvolvimento de plantas de cafeeiro ‘Catuaí Vermelho’ com idade de plantio (com seis pares de folhas).

3.3 Experimentos com o isolado $\mathrm{K}_{5}$. Avaliação da resistência de genótipos de cafeeiros ao isolado $\mathrm{K}_{5}$ de Pratylenchus coffeae.

3.3.1 Obtenção das plantas de café

3.3.2 Experimento 1, com cafeeiro 'Mundo Novo'.

3.3.3 Experimentos 2 e 3, com cafeeiros 'Robusta'

3.3.4 Experimentos 4 e 5, com cafeeiros 'Conilon'

3.4.1 Experimentos com isolado $\mathrm{M}_{2}$ de Pratylenchus coffeae......

3.4.2 Experimentos com isolado $\mathrm{K}_{5}$ de Pratylenchus coffeae.

4.1 Experimentos com o isolado $\mathrm{M}_{2}$ de Pratylenchus coffeae.

4.1.1 Experimento com plântulas de cafeeiro 'Catuaí Vermelho'

4.1.2 Experimento com plantas de cafeeiro 'Catuaí Vermelho’

4.2 Experimentos com o isolado $\mathrm{K}_{5}$ de Pratylenchus coffeae.

4.2.1 Experimento 1, com cafeeiro 'Mundo Novo'

4.2.2 Experimentos 2 e 3, com cafeeiro 'Robusta'

4.2.3 Experimentos 4 e 5, com cafeeiro 'Conilon' 


\section{LISTA DE FIGURAS}

Página

1 Produção de Café - Safra 2003/2004. Participação em porcentagem por estado.

2 Altura das plântulas de cafeeiro 'Catuaí Vermelho' inoculadas com diferentes densidades populacionais $(\mathrm{Pi}=0,333,1.000$, 3.000 e 9.000 nematóides/plântula) do isolado $\mathrm{M}_{2}$ de Pratylenchus coffeae

3 Massa fresca do sistema radicular (MFSR) de plântulas de cafeeiro ‘Catuaí Vermelho’ inoculadas com diferentes densidades populacionais $(\mathrm{Pi}=0,333,1.000,3.000$ e 9.000 nematóides/ plântula) do isolado $\mathrm{M}_{2}$ de Pratylenchus coffeae.

4 Massa seca da parte aérea (MSPA) de plântulas de cafeeiro 'Catuaí Vermelho' inoculadas com diferentes densidades populacionais $(\mathrm{Pi}=0,333,1.000,3.000$ e 9.000 nematóides/ plântula) do isolado $\mathrm{M}_{2}$ de Pratylenchus coffeae. 


\section{LISTA DE TABELAS}

Página

1 Médias de altura (ALT), massa fresca do sistema radicular (MFSR) e massa seca da parte aérea (MSPA) de plantas de cafeeiro ‘Catuaí Vermelho’ inoculadas com diferentes densidades populacionais (Pi) do isolado $\mathrm{M}_{2}$ de Pratylenchus coffeae e valores de variação populacional (Pf/Pi) obtidos para os nematóides nos diversos tratamentos.............................................

2 Variação populacional (Pf/Pi) de Meloidogyne incognita raça 2 (Mi) e do isolado $\mathrm{K}_{5}$ de Pratylenchus coffeae $\left(\mathrm{K}_{5}\right)$ nos diferentes genótipos de cafeeiros testados

3 Efeitos de Meloidogyne incognita raça 2 (Mi) e do isolado $\mathrm{K}_{5}$ de Pratylenchus coffeae $\left(\mathrm{K}_{5}\right)$ na massa seca da parte aérea (MSPA) e massa fresca das raízes (MFR) dos cafeeiros após sete meses da inoculação...... 


\section{Pratylenchus coffeae EM CAFEEIROS: EFEITO DE DENSIDADES POPULACIONAIS DO NEMATÓIDE E TESTES COM GENÓTIPOS}

Autora: MELISSA DALL'OGLIO TOMAZINI

Orientador. Prof. Dr. LUIZ CARLOS CAMARGO BARBOSA FERRAZ

\section{RESUMO}

O nematóide das lesões Pratylenchus coffeae é um dos principais parasitos do cafeeiro e de outras culturas e sua variabilidade biológica, que dificulta a adoção de métodos de controle, contribui para aumentar a sua importância no Brasil. Pela importância da cafeicultura e a falta de estudos com esse nematóide no Brasil, foram realizados experimentos com dois de seus isolados $\left(\mathrm{K}_{5}\right.$ e $\mathrm{M}$ ), com os objetivos de correlacionar densidades populacionais do nematóide aos danos causados e estabelecer possíveis fontes de resistência de cafeeiros ao isolado $\mathrm{K}_{5}$. Foram testadas diferentes densidades populacionais iniciais do isolado $\mathrm{M}_{\mathbf{2}}$ em plantas (seis pares de folhas) e plântulas (dois pares de folhas) do cafeeiro arábico 'Catuaí Vermelho'. As densidades populacionais utilizadas foram de $0,333,1.000,3.000$ e 9.000 nematóides por plântula ou planta. A avaliação ocorreu aproximadamente cinco (plântulas) e sete (plantas) meses após a inoculação. Os resultados mostraram que houve uma acentuada redução do crescimento das plântulas, bem como massa fresca das raízes e massa seca da parte aérea, já a partir das densidades mais baixas. A variação populacional (Pf/Pi) foi menor que um $(1,0)$ para todas as densidades de inóculo, indicando que esta cultivar, no estágio 
de plântulas com dois pares de folhas, mostrourse intolerante ao parasitismo. Em relação à inoculação das plantas, já com seis pares de folhas, não houve diferenças significativas nas variáveis analisadas e ocorreram decréscimos populacionais do nematóide, indicando que, nessas condições, 'Catuaí Vermelho' mostrou se resistente ao isolado $\mathrm{M}_{2}$. Em relação ao isolado $\mathrm{K}_{5}$, foram realizados cinco experimentos, visando caracterizar as reações de genótipos de Coffea canephora ('Robusta' e 'Conilon'), além de $C$. arabica 'Mundo Novo', comparado às reações frente ao nematóide de galhas Meloidogyne incognita raça 2. No Experimento 1, foram utilizadas plantas de C. arabica 'Mundo Novo', inoculadas com 1.480 nematóides por planta (isolado $\mathrm{K}_{5}$ e $M$. incognita). Após sete meses da inoculação foi feita a avaliação, mostrando que o crescimento populacional dos nematóides foi alto e a reação de suscetibilidade. Mesmo em mudas desenvolvidas de cafeeiro 'Mundo Novo', o isolado $K_{5}$ destacou-se como tão agressivo quanto $M$. incognita. Os outros genótipos testados, de C. canephora, foram inoculados com 3.000 nematóides por planta. Nos Experimentos 2 e 3, as linhagens IAC 4804 e IAC 4810 de 'Robusta' foram suscetíveis ao isolado K5, mas em um deles (IAC 4804) ocorreu grande variação entre as repetições em relação à $M$. incognita. Apenas o isolado $\mathrm{K}_{5}$ promoveu redução do crescimento do cafeeiro, evidenciado na variável massa fresca das raízes, em ambas as linhagens, sendo que IAC 4810 comportourse como resistente a $M$. incognita. No caso de C. canephora 'Conilon', ambas as linhagens testadas (IAC 4764 e IAC 4765) foram resistentes ao isolado $K_{5}$ e suscetíveis a $M$. incognita. 


\title{
Pratylenchus coffeae IN COFFEE PLANTS: EFFECT OF INITIAL POPULATION DENSITIES AND TESTS WITH GENOTYPES
}

\author{
Author: MELISSA DALL'OGLIO TOMAZINI \\ Adviser: Prof. Dr. LUIZ CARLOS CAMARGO BARBOSA FERRAZ
}

\section{SUMMARY}

The lesion-nematode Pratylenchus coffeae is a major pest of coffee and other economic crops and its biological variability, which often makes difficult the adoption of control methods, contributes to increase the importance of this parasite in Brazil. Due to the importance of coffee production and the lack of studies involving this nematode species in Brazil, experiments were set with two of its available isolates ( $\mathrm{K}_{5}$ and $\mathrm{M}$ ) to correlate initial population densities with the damage caused on coffee plants and to establish possible resistance sources in relation to the isolate $\mathrm{K}_{5}$.

Different population densities of isolate $\mathrm{M}_{2}$ were tested in plants (six pairs of leaves) and seedlings (two pairs of leaves) of Coffea arabica 'Catuaí Vermelho'. The population densities (Pi) were: 0, 333, 1.000, 3.000 and 9.000 nematodes per seedling or plant. The evaluation was done at approximately five (seedlings) and seven (plants) months after inoculation. The results showed that there was a marked reduction of the height, as well as root fresh weight and shoot dry weight of the seedlings, starting from the lower Pi values. The nematode population decreased $(\mathrm{Pf} / \mathrm{Pi}<1)$, indicating that this cultivar, at the seedling stage, was intolerant to parasitism. In relation to the inoculation 
of older plants, there were no significant differences in the growth parameters and the nematode population also decreased allowing 'Catuaí Vermelho' to be rated as resistant to the isolate $\mathbf{M}_{2}$. In relation to isolate $\mathrm{K}_{5}$, five experiments (referred to as $1,2,3$, 4, and 5) were set to characterize the reaction of different genotypes of Coffea canephora ('Robusta' and 'Conilon') and C. arabica 'Mundo Novo', as compared with their reaction to the root-knot nematode Meloidogyne incognita race 2. In Experiment 1, plants of $C$. arabica 'Mundo Novo' were inoculated with 1,480 nematodes per plant ( $\mathrm{K}_{5}$ and $M$. incognita). The final evaluation after seven months of the inoculation showed a high populational increase of the nematodes and that both were pathogenic at a same extent. The other genotypes tested, belonging to C. canephora, were inoculated with 3,000 nematodes per plant. The genotypes (IAC 4804 and IAC 4810) of 'Robusta' were susceptible to isolate $\mathrm{K}_{5}$, but in one of them (IAC 4804) there was great variation among the repetitions in relation to $M$. incognita. The isolate $\mathrm{K}_{5}$ caused marked reduction in the growth of coffee Robusta plants as evidenced particularly through the root fresh weight values in both tested genotypes; in addition, IAC 4810 was rated as resistant to $M$. incognita. With regard to C. canephora 'Conilon', both tested genotypes (IAC 4764 and IAC 4765) were resistant to isolate $\mathrm{K}_{5}$ and susceptible to $M$. incognita. 


\section{INTRODUÇÃO}

Atualmente o cafeeiro é cultivado comercialmente em 54 países, sendo Colômbia, Brasil, Vietnã e Indonésia, nessa ordem, os maiores produtores. O estado de Minas Gerais lidera a produção de café arábico (Coffea arabica L.) e o Espírito Santo é o principal produtor de C. canephora Pierre no Brasil (Figura 1). Nos últimos dez anos, houve expressivo aumento na produção brasileira de café, que passou de 18 milhões de sacas anuais, no período de 1992 a 1996, para 35 milhões de sacas no biênio de 2002 a 2003 (Dutra, 2003). Portanto a cultura do café ainda é uma das principais atividades econômicas do Brasil.

Os nematóides fitoparasitos são fatores limitantes da cultura do café, pelo seu potencial patogênico e difícil controle. No Brasil, estão disseminados em todas as regiões cafeeiras, principalmente Meloidogyne spp. e Pratylenchus spp., causando perdas estimadas em $20 \%$ (Lordello, 1976). Dada a baixa eficiência dos nematicidas no controle dos nematóides do cafeeiro, exceto Meloidogyne exigua Goeldi, 1892, seu manejo é baseado no uso de genótipos resistentes. Nesse particular, deve-se destacar a cultivar 'IAC Apoatã' de C. canephora, imune a M. exigua e resistente a $M$. incognita (Kofoid e White, 1919) Chitwood, 1949 (Gonçalves, 1993). Esse genótipo também é valioso para o controle de $M$. exigua e, principalmente, $M$. incognita em cafeeiro arábico, pois tem sido utilizado como porta-enxerto de C. arabica no Brasil. Entretanto, 
Figura 1. Produção de Café - Safra 2003/2004: Participação por estado (em \%)

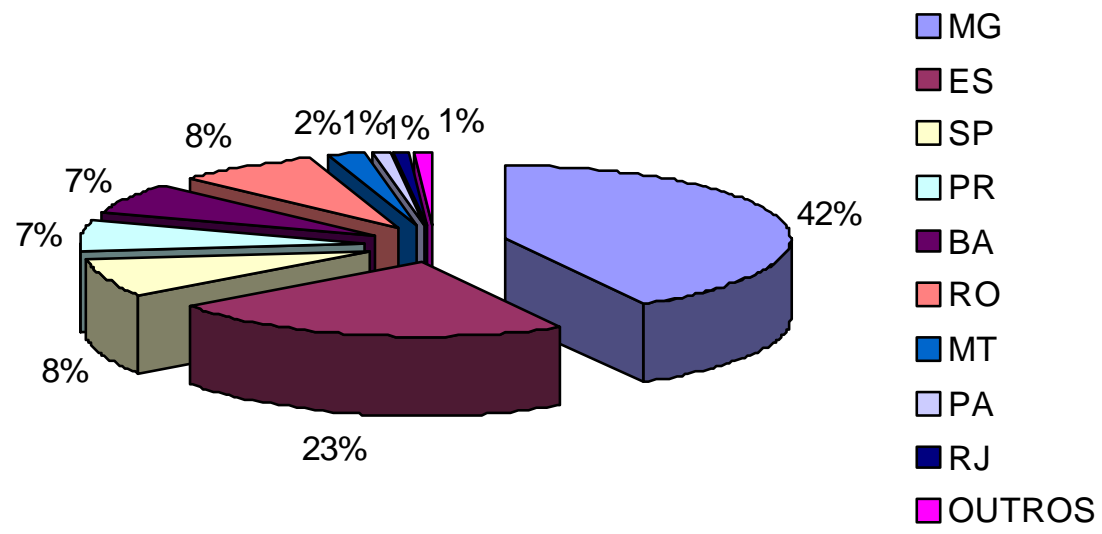

[ Elaboração: CONAB]

não há informações disponíveis sobre os cafeeiros cultivados no Brasil em relação a Pratylenchus coffeae (Zimmermann, 1898) Filipjev \& Schuurmans Stekhoven, 1941, diferentemente do que ocorre em países da América Central, em que genótipos resistentes têm sido utilizados para o controle dessa espécie de nematóide das lesões (Villain et al., 2002). A manutenção de tal situação não se justifica, pois há relatos de campo e trabalhos experimentais demonstrando a ocorrência e patogenicidade de $P$. coffeae no Brasil (Monteiro e Lordello, 1974; Inomoto et al., 1998; Kubo et al., 2001; 2003). Nesse particular, há de se destacar a variação biológica existente entre as 
populações de $P$. coffeae em relação às plantas hospedeiras (Silva e Inomoto, 2002) e mesmo em relação à agressividade ao cafeeiro (Kubo et al., 2003).

Em função do exposto e dentro da linha de pesquisa de comportamento e resistência de cafeeiros a $P$. coffeae, conduziu-se o presente estudo, dividido em duas partes. A primeira envolveu dois experimentos, em que foi avaliado o efeito de densidades populacionais de um isolado pouco agressivo (ao cafeeiro) de $P$. coffeae no crescimento de C. arabica 'Catuaí Vermelho'. A segunda parte foi um estudo visando avaliar a suscetibilidade de quatro genótipos de C. canephora, além de confirmar a suscetibilidade de C. arabica 'Mundo Novo', a um isolado muito agressivo (ao cafeeiro) de $P$. coffeae. Para que as informações obtidas nesse estudo fossem mais úteis e completas, os mesmos genótipos foram também testados em relação a $M$. incognita. 


\section{REVISÃO DE LITERATURA}

\subsection{Generalidades}

Entre as aproximadamente 100 espécies descritas do gênero Coffea, somente duas produzem frutos com importância econômica no mercado mundial: $C$. arabica e $C$. canephora. Outras espécies, como C. congensis Froehner, C. eugenioides Moore, $C$. liberica Hiern., C. dewevrei De Wild et Dur., C. racemosa Lour., apesar de não serem cultivadas economicamente, por possuírem características importantes, como resistência a pragas, doenças e nematóides, tolerância a seca etc., são valiosas em programas de melhoramento (Fazuoli, 1986).

A espécie mais plantada no mundo é C. arabica, com $70 \%$ dos cafeeiros cultivados. É favorecida por altitudes entre 500 e $1.000 \mathrm{~m}$ e temperaturas médias anuais entre 19 e $22{ }^{\circ} \mathrm{C}$. Especula-se que a origem de C. arabica seja a hibridação natural entre C. eugenioides e C. congensis ou entre $C$. eugenioides e C. canephora. O primeiro genótipo de expressão no Brasil foi chamado de 'Nacional' ou 'Típica', que deu origem a cultivares importantes como 'Maragogipe' e 'Amarelo de Botucatu', mas manteve-se como o cafeeiro mais plantado até meados do século XIX, época da introdução da cultivar 'Bourbon Vermelho', proveniente da Ilha de Reunião. Outra importante cultivar introduzida foi a Sumatra, principalmente por ter originado, por hibridação natural com 'Bourbon Vermelho', a cultivar Mundo Novo, selecionada em 1931 e atualmente o 
segundo genótipo mais cultivado de C. arabica. Outros genótipos que merecem ser citados, pela relevância nos dias de hoje, são 'Acaiá' e o mais importante deles, 'Catuaí', com suas variantes vermelha e amarela (Simon, 1999).

No Brasil, C. canephora passou a ser explorada comercialmente a partir da década de 60 do século passado, com o objetivo de cultivo de cafeeiro em áreas impróprias para C. arabica, ou seja, com temperaturas médias anuais acima de $22{ }^{\circ} \mathrm{C}$ ou altitudes abaixo de 500 m. O genótipo ‘Conilon’ é o mais plantado no Brasil atualmente, mas há outros que merecem ser citados: 'Robusta', 'Guarani', 'Laurete', 'Oka', 'Bukobensis', 'Uganda', 'Crassifolia' e 'Ambriz'. Espírito Santo é o maior estado produtor brasileiro de C. canephora, com $70 \%$ do total, seguindo-se Rondônia (23\%), Bahia (3,6 \%) e Minas Gerais (1,3\%) (Matiello e Barros, 1998). A espécie C. canephora apresenta genótipos com ampla variação em características como ciclo, porte e arquitetura da planta, tamanho e forma dos frutos, folha e sementes. Em relação ao cafeeiro arábico, é mais tolerante a condições adversas, como seca e ataque de pragas, doenças e nematóides (Simon, 1999). Apesar de produzir bebida de qualidade inferior ao café arábico, o fruto de C. canephora é amplamente utilizado na indústria de café solúvel e também em "blends" (mistura) com arábico, pois possui maiores teores de sólidos solúveis e seu preço é mais baixo, barateando o custo do produto final (Fazuoli, 1986). Além disso, foi utilizada para a produção de vários híbridos com C. arabica, destacando-se 'Icatu', 'Obatã', 'Tupi' e 'Iapar 59', que herdaram de C. canephora a resistência à ferrugem. 


\subsection{Nematóides do Cafeeiro}

Com importância freqüentemente subestimada devido ao pequeno tamanho, e conseqüente difícil visualização, além dos sintomas pouco específicos, os nematóides são considerados, desde a década de 70 do século passado até os dias de hoje, os principais agentes limitantes da cultura do café no Brasil. Segundo Campos et al. (1990), os principais nematóides do cafeeiro no Brasil são os nematóides de galhas [Meloidogyne exigua, M. coffeicola Lordello \& Zamith, 1960, M. incognita e M. hapla Chitwood, 1949] e os nematóides das lesões radiculares [Pratylenchus brachyurus (Godfrey, 1929) Filipjev \& Schuurmans Stekhoven, 1941 e P. coffeae]. Mais recentemente, um biótipo de $M$. incognita foi elevado ao nível de espécie: $M$. paranaensis Carneiro, Carneiro, Abrantes, Santos e Almeida, 1996. O nematóide cavernícola [Radopholus similis (Cobb, 1893) Thorne, 1949] e o nematóide reniforme [Rotylenchulus reniformis Linford \& Oliveira, 1940] já foram relatados em cafeeiro no Brasil, mas desconhece-se a patogenicidade para essa rubiácea. Em levantamento recente em cafezais do estado de São Paulo, Meloidogyne spp. e Pratylenchus spp. ocorreram em, respectivamente, 56 e $29 \%$ de 195 amostras (Kubo et al., 2001).

Como citado acima, o manejo do cafeeiro em áreas infestadas com fitonematóides é baseado no uso de cultivares resistentes. Moderada resistência a $M$. incognita era conhecida em genótipos de C. canephora e algumas linhagens de 'Icatu' (Fazuoli et al., 1983). Por outro lado, trabalhos de campo mostraram que 52 linhagens de 'Icatu' eram suscetíveis e sensíveis a $M$. incognita raça 2 e nove eram suscetíveis e tolerantes, não podendo ser recomendadas em áreas infestadas com o nematóide (Carneiro, 1995). O 
primeiro genótipo com níveis razoáveis de resistência a $M$. incognita foi a cultivar IAC Apoatã de C. canephora (Gonçalves et al., 1996).

Há vários genótipos de C. canephora e híbridos de C. arabica com C. canephora resistentes a $M$ exigua. Segundo Morera e Lopez (1987), materiais como 'Robusta T3759' e 'Sarchimor T5296' são resistentes a M. exigua. Estudos no Brasil demonstraram que C. canephora 'IAC Apoatã' é imune a esse nematóide (Gonçalves, 1993). Todavia, o uso de genótipos resistentes a M. exigua não é corrente no Brasil, pois nematicidas propiciam controle satisfatório. Em cafeeiro arábico 'Mundo Novo', com 18 anos de idade e infestado com $M$. exigua e $M$. coffeicola, casudafós, carbofurano e carbosulfano foram eficientes no controle dos nematóides (Volpato et al ., 2001).

\subsection{Importância dos nematóides das lesões no Brasil}

No contexto mundial, $P$. coffeae é considerado o nematóide do gênero Pratylenchus mais patogênico ao cafeeiro, pois está amplamente disseminado em áreas cafeeiras, principalmente na Índia e em países da América Central (Badel \& Ayala, 1980; Campos et al., 1990; Kumar \& Samuel, 1990; Schieber \& Grullon, 1969). O Brasil constitui exceção, pois $P$. brachyurus está mais disseminado que $P$. coffeae em cafezais (Gonçalves et al., 1987; Kubo et al., 2001).

O primeiro relato de P. coffeae no Brasil foi feito por Monteiro e Lordello (1974), em raízes de cafeeiro coletadas em Marília, Estado de São Paulo, onde se encontraram cafeeiros subdesenvolvidos, com sintomas de deficiência de minerais e sistema radicular pobre, além de plantas mortas. Posteriormente, foi assinalado nos municípios de Presidente Prudente e Valinhos, Estado de São Paulo, e no município de Barra da 
Guabiraba no Estado de Pernambuco (Kubo, 2002; Moura et al., 2002). Em Pernambuco, os cafeeiros examinados, com 1,5 ano de idade, apresentavam, além de lesões do córtex das raízes, severas lesões no colo das plantas.

Estudos sobre P. coffeae devem levar em conta a variação biológica presente nesta espécie. Segundo Duncan et al. (1999), existem pronunciadas diferenças morfológicas e moleculares entre as populações de $P$. coffeae. Dois desses isolados provenientes do Brasil, um coletado de raízes de cafeeiro em Marília (nomeado $\mathrm{K}_{5}$ por Duncan et al., 1999) e outro de raízes da ornamental Aglaonema sp. (da família Araceae) do Rio de Janeiro (M2 em Duncan et al., 1999), foram estudados quanto aos hospedeiros por Silva \& Inomoto (2002). Segundo esses dois trabalhos, as diferenças morfológicas e em relação às plantas hospedeiras verificadas entre $\mathrm{K}_{5}$ e $\mathrm{M}_{2}$ sugerem que pertençam a raças ou mesmo espécies distintas entre si. Embora plantas cítricas, bananeira e cafeeiro figurem as principais plantas hospedeiras de $P$. coffeae, Silva \& Inomoto (2002) relataram limão-cravo (Citrus limonia Osbeck) e banana cv. Nanicão (Musa acuminata Colla grupo AAA) como imunes tanto a $\mathrm{K}_{5}$ como $\mathrm{M}_{2}$, enquanto o cafeeiro 'Catuaí Vermelho' foi hospedeiro pouco favorável de ambos os isolados. Aprofundando estudos sobre esses isolados com relação a cafeeiros, Kubo et al. (2003) verificaram que plântulas de cafeeiro 'Mundo Novo', com dois pares de folhas verdadeiras e inoculadas com uma população inicial (Pi) de 8.000 nematóides, apresentaram menor fotossíntese e crescimento. $\mathrm{O}$ isolado $\mathrm{K}_{5}$ mostrou-se mais agressivo ao cafeeiro que o isolado $\mathrm{M}$. $\mathrm{O}$ crescimento populacional de ambos os isolados foi negativo, comprovando que cafeeiro não é um bom hospedeiro desses isolados. No caso de $\mathrm{K}_{5}$, tal fato pode ser atribuído à população inicial excessivamente alta junto com a agressividade desse isolado, 
resultando em intensa destruição de raízes, como indicado pelos resultados de outro experimento dentro do mesmo trabalho, com diferentes densidades populacionais desse isolado ( $\mathrm{Pi}=0,333,1.000,3.000$ e 9.000 nematóides), onde nas densidades populacionais mais baixas o crescimento populacional foi elevado (para $\mathrm{Pi}=333$ e 252 dias depois da inoculação, $\mathrm{Pf} / \mathrm{Pi}=10,1)$. Recentemente, um dos isolados de $P$. coffeae que parasita citros no estado de São Paulo, estudado por Duncan et al. (1999) e que antes era conhecido como C1, foi elevado ao nível de espécie. Esse isolado mostrava-se mais agressivo em plantas de citros que outro isolado de $P$. coffeae da Flórida. Essa nova espécie foi comparada biológica, molecular e morfologicamente com $P$. coffeae e $P$. loosi Loof, 1960 e descrita como P. jaehni (Inserra et al., 2001).

Embora $\mathrm{M}_{2}$ seja menos agressivo aos cafeeiros que o isolado $\mathrm{K}_{5}$, pertence ao grupo que, segundo Duncan et al. (1999), provavelmente constitua o verdadeiro $P$. coffeae. Por enquanto esses dois isolados são considerados pertencentes à mesma espécie, mas necessitam, pelo exposto acima, serem estudados de maneira diferenciada em relação ao cafeeiro.

Por ser ainda pouco comum em cafezais do Brasil, medidas de prevenção seriam altamente eficientes para o controle de $P$. coffeae em cafeeiro. Entretanto, é importante se antecipar a problemas futuros que possam decorrer da inobservância desse cuidado e iniciar estudos básicos sobre o comportamento de outros genótipos de cafeeiros, que possam representar fontes de resistência ou tolerância a $\mathrm{K}_{5}$, ou ainda ser utilizados como porta-enxertos, no caso de C. canephora. Embora porta-enxertos resistentes já sejam utilizados em áreas infestadas por P. coffeae e espécies correlatas de Pratylenchus na Guatemala e outros países da América Central (Villain et al., 2000; 2002), esses 
resultados têm um valor restrito em nossas condições, dada a variabilidade existente dentro do chamado "grupo de P. coffeae".

Com a descoberta de que alguns cafeeiros poderiam ter genes resistentes aos nematóides que mais causam prejuízos para a cafeicultura, começaram estudos para o melhoramento das cultivares mais plantadas, pois geralmente o(s) gene(s) de resistência encontra(m)-se em espécies ou variedades que não possuem boa produtividade, não sendo economicamente rentáveis. No Brasil, o Programa de Melhoramento do Cafeeiro desenvolvido no Instituto Agronômico, gerou, ao longo de 70 anos, inúmeras cultivares importantes e de ampla utilização pelos produtores nacionais. Até o presente, os métodos utilizados para o desenvolvimento de cultivares envolviam os tradicionais processos de cruzamento e seleção de genótipos superiores, sobretudo no que abrangessem as características agronômicas desejáveis, entre elas resistência a pragas, doenças e nematóides. Cultivares como Mundo Novo, Catuaí, Icatu e Acaiá são exemplos do potencial de melhoramento tradicional para a geração de genótipos bem sucedidos comercialmente. Mas, o desenvolvimento de cultivares esbarra em limitações e, especialmente no caso dos nematóides, a mais relevante é a existência de uma estreita base genética disponível na espécie $C$. arabica. Essa limitada variação genética é decorrente de vários fatores, tal como o pequeno número de acessos utilizados na introdução da espécie no Brasil, resultando que poucas plantas deram origem às populações cultivadas no presente. Além disso, o tipo de reprodução autógama favorece a manutenção de uniformidade genética em $C$. arabica. Nas últimas décadas, o desenvolvimento e a utilização de técnicas biomoleculares, que permitem uma avaliação mais complexa de genótipos cultivados e também a identificação e a caracterização de 
genes relacionados com processos fisiológicos de importância agronômica, vêm revolucionando o melhoramento genético (Maluf et al., 2001).

No Brasil, as pesquisas visando à obtenção de cafeeiros resistentes a nematóides têm se concentrado em espécies de Meloidogyne, desconhecendo-se praticamente a reação da maioria dos genótipos em relação a $P$. coffeae. 


\section{MATERIAL E MÉTODOS}

Os experimentos relatados neste trabalho foram desenvolvidos sob condições de casa-de-vegetação na Escola Superior de Agricultura "Luiz de Queiroz”, Universidade de São Paulo, Campus de Piracicaba, SP (ESALQ/USP).

\subsection{Obtenção dos inóculos}

Os isolados $\mathrm{M}_{2}$ e $\mathrm{K}_{5}$ de Pratylenchus coffeae foram isolados em 1998 e, desde então, têm sido mantidos em calos de alfafa (Riedel et al., 1973), no laboratório de Nematologia da ESALQ/USP, Piracicaba, São Paulo. O isolado $\mathrm{M}_{2}$ foi obtido de raízes de Aglaonema sp. (ornamental da família Araceae), coletadas no município do Rio de Janeiro, RJ, em propriedade denominada Sítio Morrinhos. O isolado $\mathrm{K}_{5}$ foi obtido de raízes de cafeeiro (Coffea arabica $\mathrm{L}$.) coletadas em Marília, SP, em fazenda denominada Santa Terezinha, que vem a ser o local em que foi feito o primeiro registro de ocorrência dessa espécie no Brasil (Monteiro \& Lordello, 1974). Segundo os registros dos coletores (R.A. Silva e J.P. Pimentel), ambas as plantas apresentavam raízes muito lesionadas, indicando que os isolados eram patogênicos àqueles hospedeiros.

Para a produção dos inóculos, foram utilizadas culturas jovens (45-90 dias após a repicagem), das quais os nematóides foram extraídos pelo método de Baermann modificado para recipiente raso (Southey, 1986). As suspensões aquosas resultantes, 
contendo adultos e juvenis de $P$. coffeae, foram calibradas com adição ou retirada de água, obtendo-se as concentrações desejadas, e assim preparadas para a utilização como inóculos nos experimentos.

O isolado de Meloidogyne incognita foi obtido a partir de raízes de cafeeiro (origem: Sítio do Trevo, Município de Oswaldo Cruz, Estado de São Paulo), através da técnica de multiplicação do nematóide a partir de uma massa de ovos, em 1999, e o nematóide assim isolado tem sido mantido em raízes de tomateiro, em casa-devegetação, na ESALQ/USP, Piracicaba, São Paulo. A aplicação do teste de hospedeiros diferenciais (Taylor \& Sasser, 1978) revelou tratar-se de população da raça 2. O inóculo foi constituído de ovos e juvenis, obtido inicialmente pela trituração das raízes dos tomateiros infestados e extração pelo método de Coolen \& D’Herde (1972).

\subsection{Experimentos com o Isolado $\mathrm{M}_{2}$}

\subsubsection{Obtenção das plântulas de cafeeiro 'Catuaí Vermelho'}

As plântulas de cafeeiro Coffea arabica 'Catuaí Vermelho') foram obtidas de sementes germinadas em caixas plásticas de capacidade de 40 litros, contendo areia esterilizada em autoclave e mantidas em casa-de-vegetação. Quando as plântulas atingiram o estádio de "orelha de onça", ou seja, os cotilédones estavam totalmente expandidos, cada uma delas teve as raízes podadas, deixando-se apenas $7 \mathrm{~cm}$ da raiz principal, e foram transplantadas individualmente para recipientes plásticos de $500 \mathrm{ml}$ de capacidade, contendo $450 \mathrm{ml}$ de substrato (mistura de 1 parte de solo de textura média e 1 parte de areia média) desinfestado com brometo de metila (150 ml de $\mathrm{CH}_{3} \mathrm{Br} / 1.000$ 
litros de solo). Posteriormente, os cafeeiros foram conduzidos segundo as técnicas agronômicas convencionais, com regas diárias ou quando necessário.

\subsubsection{Experimento 1. Efeito do isolado $M_{2}$ no desenvolvimento de plântulas de cafeeiro ‘Catuaí Vermelho’ com dois pares de folhas}

Este experimento foi realizado com plântulas de cafeeiro, ou seja, quando estas apresentavam dois pares de folhas verdadeiras. $\mathrm{O}$ delineamento experimental utilizado foi inteiramente casualizado, com cinco densidades populacionais $(\mathrm{Pi}=0,333,1.000$, 3.000 e 9.000 nematóides/planta) e oito repetições, totalizando 40 parcelas. $\mathrm{Na}$ inoculação, para a densidade mais alta, a suspensão contendo os nematóides (juvenis e adultos) foi ajustada inicialmente para 3.000 nematóides por mililitro e cada plântula recebeu 9.000 nematóides através da pipetagem de $3 \mathrm{ml}$ em dois pequenos orifícios no substrato com $2 \mathrm{~cm}$ de profundidade, próximo às raízes, sobre um pequeno pedaço de lenço de papel, visando minimizar perdas de inóculo. Para as outras densidades, as suspensões foram ajustadas por meio de adição de água para, respectivamente, 1.000, 333 e 111 nematóides por mililitro e o procedimento para a inoculação foi idêntico àquele utilizado para a maior dose. Plantas não inoculadas receberam apenas água destilada. A seguir, todas as plantas foram mantidas à sombra no laboratório, por 24 horas após a inoculação, para evitar possíveis danos aos nematóides causados pelo calor e, posteriormente, transferidas para a casa-de-vegetação.

A avaliação do experimento foi realizada aos 147 dias da inoculação, incluindo as seguintes variáveis: altura das plantas, massa fresca das raízes, massa seca da parte aérea e a variação populacional. A altura das plantas foi determinada com auxílio de régua, 
considerada como a distância, no caule, entre a base e o ponto de emis são do último par de folhas. Após retiradas dos recipientes, as plantas tiveram o sistema radicular separado da parte aérea com auxílio de tesoura de poda. Os órgãos aéreos foram colocados em sacos especiais de papel, com aberturas circulares nos lados, que, depois de identificados com etiquetas, foram mantidos em estufa ajustada para $70^{\circ} \mathrm{C}$ até se ter valores constantes de massa seca. Para a obtenção dos dados de massa fresca de raízes, os sistemas radiculares foram lavados sob água corrente e depois deixados para secar à sombra por 30 minutos.

Os nematóides foram extraídos a partir de $10 \mathrm{~g}$ de raízes, segundo o método de Coolen \& D’Herde (1972), as quais foram trituradas por 1 minuto em liquidificador comum contendo $250 \mathrm{ml}$ de solução de hipoclorito a 0,5 \% (Bonetti \& Ferraz, 1981) e posteriormente passadas sucessivamente por uma peneira de 20 "mesh" (abertura da malha de $0,84 \mathrm{~mm}$ ) e outra de 500 "mesh" (abertura da malha de $0,025 \mathrm{~mm}$ ). O material retido nesta foi transferido para tubos de centrífuga de $100 \mathrm{ml}$ e a ele foi adicionado caulim (1 ml /amostra), que acelera a decantação do material desintegrado contendo os nematóides. O material foi centrifugado a 1.800 rpm por cinco minutos, para a separação da água e do material desintegrado contendo os nematóides. Esse precipitado foi ressuspendido em solução de sacarose com densidade de $1,14 \mathrm{~g} / \mathrm{ml}$ e novamente centrifugado a $1.800 \mathrm{rpm}$, desta vez por um minuto. O sobrenadante passou então por uma peneira de 500 "mesh", que reteve os nematóides. Estes foram transferidos para recipientes de vidros de $60 \mathrm{ml}$ de capacidade, contendo aproximadamente $30 \mathrm{ml}$ de amostra que foram fixados com 1,5 $\mathrm{ml}$ de formol $40 \%$ (volume/ volume) para posterior 
quantificação, com auxílio de lâmina de Peters sob microscópio óptico. Tomando-se os valores das massas totais das raízes, estimoutse a população final nas raízes.

Para a extração dos nematóides do substrato, utilizourse o método proposto por Jenkins (1964). O substrato de cada parcela foi colocado em um balde plástico, ao qual se adicionaram 5 litros de água de torneira. Esse material foi misturado e mantido em suspensão por agitação manual, seguida por 30 segundos de repouso. A seguir, a suspensão foi sucessivamente vertida nas peneiras de 20 e 400 "mesh" (abertura de malha de $0,037 \mathrm{~mm})$. O material retido na peneira de 400 "mesh" foi transferido para tubos de centrífuga, avaliados conforme citado anteriormente, exceto que nesta etapa não houve adição de caulim. Após a contagem dos nematóides assim extraídos, obtevese a estimativa da população final no substrato. A soma das populações finais nas raízes e no substrato resultou na população final do nematóide (Pf), valor utilizado para a estimativa da variação populacional (Pf/ $\mathrm{Pi})$ no experimento.

\subsubsection{Experimento 2. Efeito do isolado $M_{2}$ no desenvolvimento de plantas de cafeeiro ‘Catuaí Vermelho’ com idade de plantio (com seis pares de folhas)}

Este experimento foi realizado com plantas em idade de plantio, ou seja, com seis pares de folhas verdadeiras. O delineamento foi inteiramente casualizado, com cinco densidades populacionais $(\mathrm{Pi}=0,333,1.000,3.000$ e 9.000 nematóides/planta) e dez repetições, totalizando 50 parcelas, sendo que cada vaso com uma planta foi considerado como unidade experimental. A inoculação das plantas seguiu procedimento semelhante ao descrito no experimento 1 (subitem 3.2.2) e as plantas testemunhas, não inoculadas, receberam apenas água destilada. Também como no caso anterior, as plantas ficaram 24 
horas após a inoculação à sombra, para evitar possível dano causado pelo calor aos nematóides, e posteriormente foram transferidas para a casa de vegetação.

A avaliação do experimento foi realizada em duas etapas: a primeira, aos 68 dias da inoculação, baseando-se em quatro das dez repetições. Após 75 dias da inoculação, as plantas restantes foram transferidas a recipientes maiores contendo 1,6 1 de substrato, de modo a permitir a observação da progressão dos danos provocados pelos nematóides por período mais longo. Aos 227 dias da inoculação, foi realizada a avaliação final do experimento. Em ambas as avaliações, utilizaram-se as mesmas variáveis, métodos e análises descritos no experimento anterior, com plântulas de 'Catuaí Vermelho’.

\subsection{Experimentos com 0 isolado $\mathbf{K}$ : Avaliação da resistência de genótipos de cafeeiro ao isolado $\mathrm{K}_{5}$ de Pratylenchus coffeae}

\subsubsection{Obtenção das plantas de café}

As plantas utilizadas nesse experimento foram cedidas pelo Instituto Agronômico de Campinas (IAC). Sementes de C. arabica 'Mundo Novo' e C. canephora 'Robusta' e 'Conilon' foram colocad as para germinar em caixas plásticas de 401 de capacidade, com areia tratada com brometo de metila ( $150 \mathrm{ml}$ de $\mathrm{CH}_{3} \mathrm{Br} / 1.000 \mathrm{l}$ de substrato), em casa de vegetação do IAC. Ao atingirem o estádio de "palito de fósforo", as plântulas foram transplantadas para sacos plásticos de $500 \mathrm{ml}$, contendo substrato de textura médiaargilosa igualmente desinfestado com brometo de metila. Quando as plantas atingiram seis pares de folhas verdadeiras, foram transferidas para casa de vegetação na ESALQ/USP, Piracicaba, onde foram podadas, deixando-se, na parte aérea, os quatro 
internódios basais, e, nas raízes, os primeiros $7 \mathrm{~cm}$ a partir do colo, sendo transferidas para copos plásticos de $500 \mathrm{ml}$ de capacidade contendo aproximadamente $450 \mathrm{ml}$ de substrato (1 parte de solo de textura média para 1 parte de areia média), tratado igualmente com brometo de metila.

\subsubsection{Experimento 1, com cafeeiro 'Mundo Novo'}

Foi utilizado cafeeiro arábico 'Mundo Novo' da linhagem IAC 388-17. Na inoculação, a suspensão contendo nematóides foi ajustada para 185 nematóides por ml, sendo que cada planta recebeu 1.480 nematóides através da pipetagem de $8 \mathrm{ml} \mathrm{em}$ quatro orifícios no substrato com $2 \mathrm{~cm}$ de profundidade, próximos às raízes, sobre pequenos pedaços de lenço de papel, minimizando perdas. O delineamento experimental utilizado foi inteiramente casualizado, com três tratamentos e variando entre seis a oito repetições. Os tratamentos foram: 1) plantas infectadas com 1.480 juvenis e adultos do isolado $\mathrm{K}_{5}$; 2) plantas infectadas com 1.480 ovos e juvenis de $M$. incognita e 3) plantas não infectadas (testemunhas). Cada vaso contendo uma planta foi considerado uma parcela experimental. As plantas permaneceram 24 horas após a inoculação à sombra e foram posteriormente transferidas para casa de vegetação. Regas e adubações foram realizadas conforme a necessidade. A avaliação ocorreu aos 221 dias após a inoculação. As variáveis analisadas foram: massa seca da parte aérea, massa fresca do sistema radicular e variação populacional do nematóide, como descrito no ite m 3.2.2. 


\subsubsection{Experimentos 2 e 3, com cafeeiros 'Robusta'}

Foram realizados dois experimentos com C. canephora 'Robusta' utilizando duas linhagens: IAC 4804 e IAC 4810. O delineamento experimental foi inteiramente casualizado, com os mesmos tratamentos do experimento anterior, exceto que a população inicial foi de 3.000 nematóides por planta. Na linhagem IAC 4804, a suspensão de inóculo foi calibrada para 1.500 nematóides por ml e cada planta recebeu 2 ml, totalizando 3.000 nematóides por planta, distribuídos em dois orifícios no substrato sobre pedaços de lenço de papel. No caso de IAC 4810, a suspensão foi calibrada para 500 nematóides por $\mathrm{ml} \mathrm{e}$ cada planta recebeu $6 \mathrm{ml}$ através de quatro orifícios no substrato. Plantas testemunhas receberam água destilada. Após a inoculação, as plantas foram deixadas à sombra por 24 horas e transferidas para casa-de-vegetação. As linhagens IAC 4804 e IAC 4810 foram avaliadas aos 218 e 199 dias da inoculação, respectivamente. As variáveis analisadas foram as mesmas do experimento realizado com o cafeeiro 'Mundo Novo'.

\subsubsection{Experimentos 4 e 5, com cafeeiros 'Conilon'}

Foram realizados outros dois experimentos, cada um com uma linhagem diferente de C. canephora 'Conilon': IAC 4764 e IAC 4768. As plantas das duas linhagens foram inoculadas com uma população inicial de 3.000 nematóides, sendo a suspensão calibrada para 1.500 nematóides por $\mathrm{ml}$ e cada planta recebendo $2 \mathrm{ml}$. Todos os demais procedimentos adotados foram iguais aos descritos nos experimentos realizados com os 
cafeeiros 'Robusta', sendo que as avaliações ocorreram aos 219 e 215 dias após a inoculação, nas linhagens IAC 4764 e IAC 4765, respectivamente.

\subsection{Análises Estatísticas}

\subsubsection{Experimentos com o isolado $\mathrm{M}_{2}$ de Pratylenchus coffeae}

Os dados obtidos nos experimentos realizados com diferentes densidades populacionais do isolado $\mathrm{M}$ de $P$. coffeae foram analisados estatisticamente usando o aplicativo SANEST (CIAGRI e Departamento de Matemática e Estatística ESALQ/ USP, Piracicaba, SP), procedendo-se primeiro à análise de variância e, quando cabível, à análise de regressão entre as variáveis avaliadas em função das densidades populacionais iniciais $(\mathrm{Pi})$.

\subsubsection{Experimentos com isolado $\mathrm{K}_{5}$ de Pratylenchus coffeae}

Nos experimentos utilizando diferentes genótipos de café, as variáveis massa seca da parte aérea (MSPA) e massa fresca das raízes (MFR) foram submetidas à análise de variância, com auxílio do software SANEST (Departamento de Matemática e Estatística, ESALQ/ USP, Piracicaba, SP), e as médias comparadas pelo teste de Tukey.

Nos experimentos com ambos os isolados de P. coffeae, referidos nos itens $3.4 .1 \mathrm{e}$ 3.4.2, caracterizaram-se as reações dos cafeeiros testados com base: i) na capacidade reprodutiva do nematóide, expressa em termos da variação populacional entre a população final (Pf) e a inicial (Pi); e ii) na ocorrência ou não de redução significativa 
no desenvolvimento das plantas inoculadas com densidades populacionais iniciais crescentes $(\mathrm{Pi})$ do nematóide, baseando-se, para tanto, em valores de altura, massa fresca do sistema radicular e massa seca da parte aérea das plantas.

No caso da variação populacional, utilizoutse o critério de Oostenbrink (1966), de uso rotineiro em estudos que tratam da chamada adequação do nematóide ao hospedeiro, ou "host suitability" em inglês. Segundo esse método, as espécies ou cultivares de plantas que possibilitam a obtenção de valores de Pf/Pi iguais ou maiores que um $(1,0)$, ou seja, que permitem o aumento populacional do parasito após certo período de tempo, devem ser consideradas hospedeiras boas ou favoráveis ao nematóide, havendo quem as identifique também como suscetíveis. De modo oposto, as plantas que levam à obtenção de valores menores que um, determinando decréscimos e não aumentos populacionais, são classificadas como hospedeiras más ou desfavoráveis, ou ainda, resistentes. Plantas tidas como boas hospedeiras, ou suscetíveis (em termos de Pf/Pi), inoculadas com diferentes densidades populacionais de um dado nematóide (no caso, P. coffeae e $M$. incognita), no geral mostram redução significativa no desenvolvimento quando comparadas às testemunhas, não infectada $(\mathrm{Pi}=0)$; todavia, se não ocorrer redução significativa, a reação é dita de tolerância (= tolerantes). Da mesma forma, as plantas tidas como más hospedeiras, ou resistentes, normalmente não sofrem redução significativa no desenvolvimento, mas, quando tal ocorre, diz-se que apresentam reação de intolerância (= intolerantes).

Por fim, para comparar o isolado $\mathrm{K}_{5}$ de $P$. coffeae e $M$. incognita em relação aos potenciais reprodutivos, as médias da variação populacional foram comparadas pelo teste não-paramétrico de Wilcoxon ("Rank Sum Test”) (Campos, 1983). 


\section{RESULTADOS E DISCUSSÃO}

\subsection{Experimentos realizados com o isolado $\mathrm{M}_{2}$ de Pratylenchus coffeae}

\subsubsection{Experimento complântulas de cafeeiro 'Catuaí Vermelho'}

Houve decréscimo populacional do isolado $\mathrm{M}_{2}$ no período experimental (147 dias da inoculação): $\mathrm{Pf} / \mathrm{Pi}=0,54(\mathrm{Pi}=333) ; 0,44(\mathrm{Pi}=1.000) ; 0,46(\mathrm{Pi}=3.000) ;$ e $0,13(\mathrm{Pi}=$ 9.000). Todavia, neste experimento, o parasitismo causou significativa redução no crescimento das plantas. A análise de regressão mostrou que o modelo linear foi o que representou melhor os efeitos negativos sobre o crescimento dos cafeeiros, decorrentes da inoculação de níveis crescentes do isolado (Figuras 2 a 4).

No presente trabalho, o decréscimo populacional do isolado durante o período experimental é forte indicativo da ocorrência de reação de intolerância de parte do cafeeiro testado. Em outras palavras, as densidades de inóculo utilizadas mos traram-se críticas para plantas com apenas dois pares de folhas, ainda muito jovens e em fase bem inicial de formação do sistema radicular. Em comparação ao isolado $\mathrm{K}$, o isolado $\mathrm{M}$ pode ser considerado um parasito menos adaptado ou menos agressivo ao cafeeiro. Em experimento semelhante, Kubo et al. (2003) verificaram aumento populacional de $\mathrm{K}_{5} \mathrm{em}$ plântulas de cafeeiro 'Mundo Novo', 252 dias após inoculação de Pi = 333 (Pf/Pi = $10,1)$, indicando que o isolado $K_{5}$ multiplica-se em cafeeiro, mas necessita de um longo período de parasitismo. Por outro lado, ocorreu decréscimo populacional $(\mathrm{Pf} / \mathrm{Pi}=0,27)$ 
Figura 2. Altura das plântulas de cafeeiro 'Catuaí Vermelho' inoculadas com diferentes densidades populacionais $(\mathrm{Pi}=0,333,1.000,3.000$ e 9.000 nematóides/ plântula) do isolado $\mathrm{M}_{2}$ de Pratylenchus coffeae

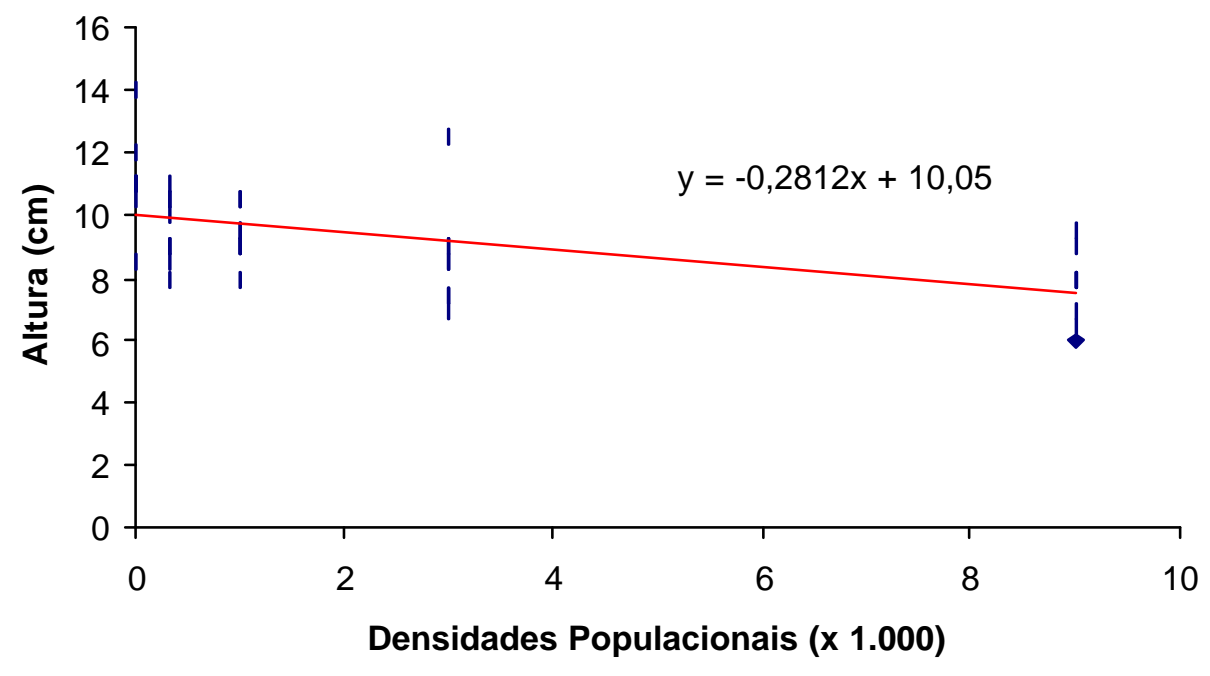

quando o inóculo foi quase dez vezes maior $(\mathrm{Pi}=3.000)$, provavelmente em decorrência da alta suscetibilidade de plântulas de cafeeiro 'Mundo Novo' a esse isolado e de processo de destruição radicular verificada, resultando em indisponibilidade de alimento ao nematóide.

\subsubsection{Experimento com plantas de cafeeiro 'Catuaí Vermelho'}

Em ambas as avaliações, ocorreu diminuição populacional do isolado $\mathrm{M}_{2}$ nas raízes do cafeeiro ‘Catuaí Vermelho’, com variação populacional entre 0,05 e 0,18, 
Figura 3. Massa fresca do sistema radicular (MFSR) de plântulas de cafeeiro 'Catuaí Vermelho' inoculadas com diferentes densidades populacionais $(\mathrm{Pi}=0,333$, 1.000, 3.000 e 9.000 nematóides/plântula) do isolado Mํ de Pratylenchus coffeae

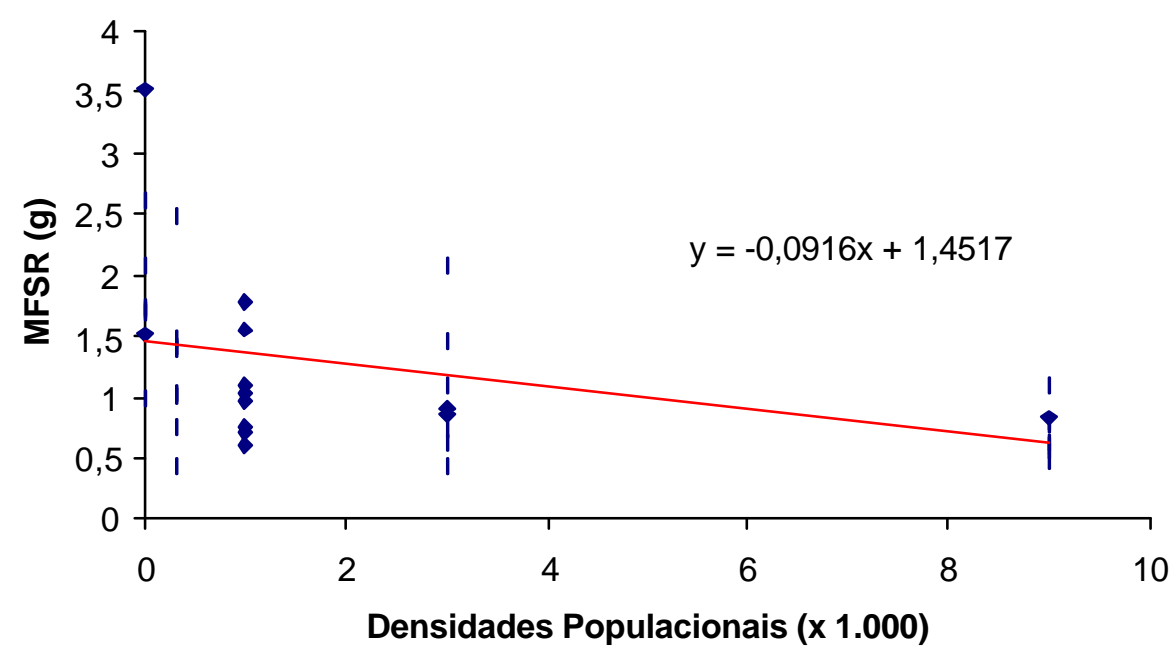

sendo, portanto, sempre bem inferiores a 1,0 (Tabela 1). Isso demonstra que, nesta fase de desenvolvimento, bem como em plântulas, a cultivar avaliada pode ser considerada hospedeira desfavorável ou resistente ao isolado. As variações ppulacionais foram bastante semelhantes às determinadas por Silva \& Inomoto (2002) para o isolado $\mathrm{M}_{2}$ na mesma cultivar (entre 0,05 e 0,15), sendo que tais autores utilizaram período semelhante ao da primeira avaliação (70 - 75 dias da inoculação), embora com um único nível de inóculo (1.000 nematóides/planta). Não houve efeito das densidades populacionais utilizadas sobre os valores médios de altura, massa fresca de raízes e de massa seca da 
Figura 4. Massa seca da parte aérea (MSPA) de plântulas de cafeeiro 'Catuaí Vermelho' inoculadas com diferentes densidades populacionais $(\mathrm{Pi}=0,333,1.000,3.000$ e 9.000 nematóides/plântula) do isolado $\mathrm{M}_{2}$ de Pratylenchus coffeae

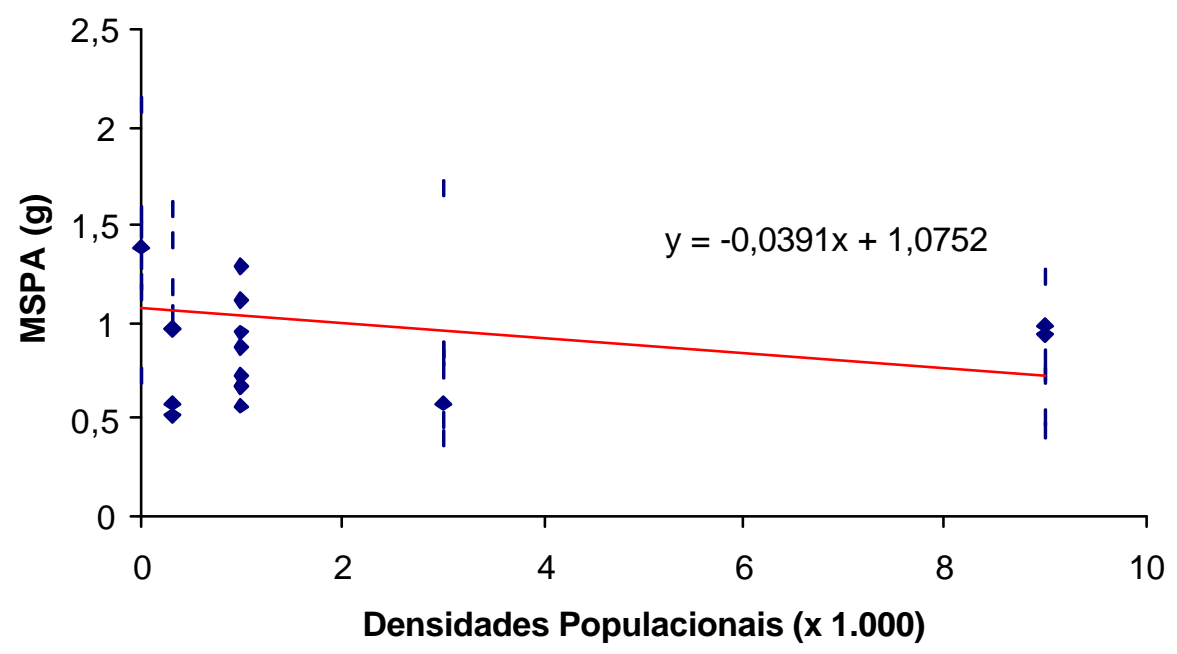

parte aérea das plantas (Tabela 1). Visualmente, também não se verificaram diferenças nos sistemas radiculares sob as diferentes densidades populacionais. $\mathrm{Na}$ segunda avaliação, também não houve diferenças significativas entre as variáveis avaliadas e, embora se extraíssem nematóides das raízes, a variação populacional manteve-se com valores de Pf/Pi menores que um. Tais resultados evidenciaram que plantas de cafeeiro arábico ‘Catuaí Vermelho’ no estádio vegetativo em que já possuíam seis pares de folhas verdadeiras mostraram reação de resistência frente ao isolado $\mathrm{M}_{2}$.

A análise conjunta dos dois experimentos demonstrou que o cafeeiro 'Catuaí Vermelho' é hospedeiro desfavorável/resistente ao isolado Mㄹ, porém, a ocorrência de 
danos significativos ao crescimento é dependente da idade, visto que a inoculação de plântulas, com apenas dois pares de folhas, resultou em reação de intolerância. Tal comportamento, ao que tudo indica, também se verifica em outros genótipos de café, como observado com plântulas de 'Mundo Novo' (Kubo et al., 2003). 
Tabela 1. Médias de altura (ALT), massa fresca do sistema radicular (MFSR) e massa seca da parte aérea (MSPA) de plantas de cafeeiro

'Catuaí Vermelho' inoculadas com diferentes densidades populacionais (Pi) do isolado $\mathrm{M}_{2}$ de Pratylenchus coffeae e valores de variação populacional (Pf/Pi) obtidos para os nematóides nos diversos tratamentos

\begin{tabular}{|c|c|c|c|c|c|c|c|c|}
\hline \multirow[b]{2}{*}{ Tratamentos $(\mathrm{Pi})^{2}$} & \multicolumn{4}{|c|}{ Primeira Avaliação (68 d.a.i.) } & \multicolumn{4}{|c|}{ Segunda Avaliação (227 d.a.i.) } \\
\hline & $\operatorname{ALT}(\mathrm{cm})$ & $\operatorname{MFSR}(\mathrm{g}){ }^{1}$ & $\operatorname{MSPA}(\mathrm{g})^{1}$ & $(\mathrm{Pf} / \mathrm{Pi})$ & $\operatorname{ALT}(\mathrm{cm})^{1}$ & $\operatorname{MFSR}(\mathrm{g}){ }^{\mathrm{I}}$ & $\operatorname{MSPA}(\mathrm{g}){ }^{1}$ & $(\mathrm{Pf} / \mathrm{Pi})$ \\
\hline 0 & 18,7 & 18,4 & 4,6 & - & 45,7 & 42,4 & 25,7 & - \\
\hline 333 & 18,7 & 14,5 & 4,8 & 0,12 & 44,9 & 45,6 & 25,9 & 0,18 \\
\hline 1.000 & 18,6 & 16,5 & 4,8 & 0,11 & 44,5 & 34,3 & 24,9 & 0,12 \\
\hline 3.000 & 18,9 & 17,1 & 4,9 & 0,16 & 44,8 & 42,9 & 26,1 & 0,13 \\
\hline 9.000 & 18,9 & 14,6 & 4,4 & 0,05 & 45,4 & 51,2 & 28,1 & 0,05 \\
\hline
\end{tabular}

${ }^{1}$ Valores de F não significativos para todas as variáveis, nas épocas avaliadas, seguindo a análise de variância. ${ }^{2}$ Nematóides por planta. 


\subsection{Experimentos realizados com o isolado $\mathrm{K}_{5}$ de Pratylenchus coffeae}

\subsubsection{Experimento 1, com cafeeiro 'Mundo Novo'}

A variação populacional foi maior para $M$. incognita raça $2(\mathrm{Pf} / \mathrm{Pi}=158,9)$ que para o isolado $\mathrm{K}_{5}$ de $P$. coffeae ( $\left.\mathrm{Pf} / \mathrm{Pi}=47,8\right)$, mas o cafeeiro 'Mundo Novo', linhagem IAC 388-17, foi igualmente afetado por ambos os nematóides na população inicial utilizada ( $\mathrm{Pi}=1.480$ ), em relação às variáveis massa seca da parte aére a e massa fresca das raízes, quando comparadas às plantas não infectadas (Tabela 3 ). As raízes infectadas com o isolado $\mathrm{K}_{5}$ exibiam raízes secundárias escurecidas, principalmente perto da raiz principal. Além disso, os sistemas radiculares eram menos volumosos quando comparados aos das plantas não infectadas. As raízes das plantas com $M$. incognita apresentavam galhas pequenas nas extremidades das raízes secundárias.

Os resultados em relação a $M$. incognita estão em concordância com relatos anteriores. Lordello \& Lordello (1987) verificaram que C. arabica 'Mundo Novo', 'Catuaí Amarelo', 'Catuaí Vermelho' e 'Caturra', e C. canephora 'Guarani' e 'Conilon' foram suscetíveis a $M$. incognita, observando ainda que a raça 2 foi a mais agressiva, seguida da raça 1 . Com relação ao isolado $\mathrm{K}_{5}$ os resultados concordam com os relatados por Kubo et al. (2003), que estudaram o efeito desse isolado em cafeeiro 'Mundo Novo'. Plântulas com dois pares de folhas mostraram-se intolerantes ao isolado na densidade de 8.000 nematóides/plântula, verificando-se decréscimo populacional do nematóide $(\mathrm{Pf} / \mathrm{Pi}<1)$, decréscimo esse atribuído ao estado das raízes, praticamente destruídas em toda sua extensão devido à atividade do nematóide. Os presentes resultados demonstram que também cafeeiros mais velhos, ou seja, com seis pares de folhas, são suscetíveis ao isolado $\mathrm{K}_{5}$, mesmo em densidades populacionais mais baixas $(\mathrm{Pi}=1.480)$ que as utilizadas por Kubo et al. $(2003)$. Os resultados da variação 
populacional de $\mathrm{K}_{5}$ evidenciam que há forte dependência da disponibilidade do alimento, ou seja, raízes, pois, diferentemente do trabalho de Kubo et al. (2003), no presente estudo houve elevado crescimento populacional de $\mathrm{K}_{5}$ apesar do pronunciado efeito deletério sobre o crescimento do cafeeiro 'Mundo Novo'. Destaque-se que tal efeito foi similar ao causado por M. incognita raça 2 em igualdade de condições. Portanto, o isolado $\mathrm{K}_{5}$ de $P$. coffeae, ao contrário do $\mathrm{M}_{2}$, deve ser motivo de grande preocupação aos cafeicultores. No caso de uma reforma ou mesmo na implantação de novos cafezais, quando mudas com cinco ou seis pares de folhas são utilizadas, o isolado $\mathrm{K}_{5}$ de $P$. coffeae é potencialmente tão daninho quanto $M$. incognita, relatada como a espécie mais disseminada e agressiva ao cafeeiro (Campos et al., 1990).

\subsubsection{Experimentos 2 e 3, com cafeeiros 'Robusta'}

A linhagem IAC 4804 foi suscetível ao isolado $\mathrm{K}_{5}$ e a $M$. incognita, mas com grande variação entre as repetições em relação à esta última espécie; a variação populacional deste ficou entre 0,1 a 0,4 em seis repetições e foi de 29,2 e 32,6 em duas, ou seja, a maioria das repetições comportourse como resistente à $M$. incognita (Tabela 2). Apenas o isolado $\mathrm{K}_{5}$ de $P$. coffeae promoveu redução do crescimento (Tabela 3), na massa fresca das raízes (MFR), sendo que os sistemas radiculares parasitados exibiam escurecimento nas raízes secundárias e eram menos volumosos, quando comparados aos das plantas testemunhas e das infectadas por M. incognita. Portanto, a linhagem IAC 4804 poderia ser considerada tolerante a $M$. incognita com base na média da variação populacional (Pf/Pi), mas a variabilidade observada entre os valores obtidos para as repetições sugere que o ideal seria a realização de um novo estudo visando melhor esclarecer tal aspecto. Em relação a $\mathrm{K}_{5}$, mostrou-se suscetível tanto do ponto 
de vista de adequação hospedeira como de danos causados, com base na redução significativa na massa fresca de raízes.

A linhagem IAC 4810 foi suscetível ao isolado $\mathrm{K}_{5}$ de $P$. coffeae e resistente à $M$. incognita. Houve variação entre as repetições em relação ao isolado $\mathrm{K}_{5}$ (Tabela 2), mas em todas as repetições os valores de Pf/Pi foram maiores que um, situando-se entre 1,4 e 21,0. Como com a IAC 4804, apenas $\mathrm{K}_{5}$ afetou o crescimento das plantas, reduzindo significativamente a massa fresca das raízes (Tabela 3). Portanto, IAC 4810 pode ser considerada resistente a $M$. incognita raça 2 e suscetível ao isolado $\mathrm{K}_{5}$ de $P$. coffeae.

\subsubsection{Experimentos 4 e 5, com cafeeiros 'Conilon'}

As duas linhagens de 'Conilon' testadas, IAC 4764 e IAC 4765, fram resistentes ao isolado $\mathrm{K}_{5}$ de $P$. coffeae (Tabelas 2 e 3). Porém, a população de $M$. incognita aumentou em ambas (Tabela 2), muito mais em IAC $4764(\mathrm{Pf} / \mathrm{Pi}=$ 20,8) que em IAC $4765(\mathrm{Pf} / \mathrm{Pi}=1,51)$; além disso, ocorreu grande variação entre as repetições (Pf/Pi = 0-161,4 em IAC 4764 e 0,16,31 em IAC 4765). Como a massa seca da parte aérea (MSPA) e a massa fresca das raízes (MFR) das duas linhagens não foram afetadas por $M$. incognita, podem ser consideradas tolerantes (Tabela 3). As raízes de ambas as linhagens de 'Conilon' infectados com o isolado $\mathrm{K}_{5}$ e $M$. incognita não apresentaram escurecimento aparente, confirmando a tolerância a ambos os nematóides.

Segundo Villain et al. (2000), são conhecidas progênies de C. canephora 'Robusta' com resistência parcial a $P$. coffeae na Índia e progênies de $C$. canephora 'Robusta' altamente resistentes a $P$. coffeae na Indonésia. Uma vez que não são conhecidos genótipos de $C$. arabica resistentes a $P$. coffeae, a enxertia em C. canephora é uma possível alternativa de 
manejo e que tem se mostrado eficaz em condições de campo na Guatemala. (Villain et al., 2000; 2002). Provavelmente, futuros trabalhos sobre a resistência de genótipos de cafeeiros a $P$. coffeae devam levar em conta a variação biológica existente dentro dessa espécie de nematóide. No presente trabalho, os dois genótipos 'Robusta' testados foram suscetíveis ao isolado $\mathrm{K}_{5}$ e os dois de 'Conilon' foram resistentes. Portanto, os dois últimos podem ser valiosos no futuro como fontes de resistência e no presente como porta-enxertos, embora apresentem a desvantagem de serem suscetíveis a $M$. incognita, pelo menos à raça 2 , utilizada no presente trabalho. Nesse particular, é importante destacar a grande variação observada nos valores de Pf/Pi dentro das linhagens testadas em relação a $M$. incognita, apesar de tanto IAC 4765 quanto IAC 4764 terem sido consideradas suscetíveis, pois o Pf/Pi médio foi superior a 1. Essa heterogeneidade não constitui novidade e está amplamente registrada na literatura (Rebel \& Fazuoli, 1978; Fazuoli et al., 1983; Gonçalves et al., 1990; Costa et al., 1991; Gonçalves, 1993; Carneiro, 1995). Sob o ponto de vista prático, tal fato demonstra a possibilidade de seleção de plantas matrizes resistentes a ambos os nematóides. No caso de $C$. canephora 'Robusta', a suscetibilidade a K5 não deve ser vista como indicativo da inexistência de genótipos resistentes dentro desse grupo de C. canephora, pois o número de genótipos testados foi muito pequeno. 
Tabela 2. Variação populacional (Pf/Pi) de Meloidogyne incognita raça 2 (Mi) e do isolado $\mathrm{K}_{5}$ de Pratylenchus coffeae (K5) nos diferentes genótipos de cafeeiros testados

\begin{tabular}{|c|c|c|c|c|c|}
\hline \multirow[b]{3}{*}{ Tratamentos } & \multirow[b]{2}{*}{ Mundo Novo } & \multicolumn{2}{|c|}{ Robusta } & \multicolumn{2}{|c|}{ Conilon } \\
\hline & & 4804 & 4810 & 4764 & 4765 \\
\hline & $\mathrm{Pf} / \mathrm{Pi}^{\mathrm{I}}$ & $\mathrm{Pf} / \mathrm{Pi}^{1,2}$ & $\mathrm{Pf} / \mathrm{Pi}^{1,2}$ & $\mathrm{Pf} / \mathrm{Pi}^{\mathrm{i}, 2}$ & $\mathrm{Pf} / \mathrm{P}^{\mathrm{i}, 2}$ \\
\hline Mi & $158,9 \mathrm{a}^{3}$ & 7,9 & $0,02 \mathrm{~b}$ & $20,8 \mathrm{a}$ & $1,51 \mathrm{a}$ \\
\hline $\mathrm{K}_{5}$ & $47,8 b^{4}$ & 7,4 & $11,57 \mathrm{a}$ & $0,01 \mathrm{~b}$ & $0,02 \mathrm{~b}$ \\
\hline $\mathrm{P}>\mathrm{F}$ & 0,0018 & 0,1040 & 0,0020 & 0,050 & 0,0020 \\
\hline
\end{tabular}

${ }^{1}$ Médias seguidas de mesma letra na coluna não diferem entre si pelo teste de Wilcoxon. ${ }^{2}$ Médias de 8 repetições. ${ }^{3}$ Médias de 7 repetições. ${ }^{4}$ Médias de 5 repetições. 
Tabela 3. Efeitos de Meloidogyne incognita raça 2 (Mi) e do isolado $\mathrm{K}_{5}$ de Pratylenchus coffeae (K5) na massa seca da parte aérea (MSPA) e massa fresca das raízes (MFR) dos cafeeiros após sete meses da inoculação

\begin{tabular}{|c|c|c|c|c|c|c|c|c|c|c|}
\hline \multirow[b]{3}{*}{ Tratamentos } & & & \multicolumn{4}{|c|}{ Robusta } & \multicolumn{4}{|c|}{ Conilon } \\
\hline & \multicolumn{2}{|c|}{ Mundo Novo } & \multicolumn{2}{|c|}{4804} & \multicolumn{2}{|c|}{4810} & \multicolumn{2}{|c|}{4764} & \multicolumn{2}{|c|}{4765} \\
\hline & MSPA $^{1}$ & $\mathrm{MFR}^{1}$ & MSPA $^{1,2}$ & $\mathrm{MFR}^{1,2}$ & MSPA $^{1,}$ & $\mathrm{MFR}^{1,2}$ & MSPA $^{1,2}$ & MFR $^{1,2}$ & MSPA $^{1,2}$ & $\mathrm{MFR}^{1,2}$ \\
\hline Testemunha & $22,7 a^{2}$ & $30,4 \mathrm{a}$ & $14,2 \mathrm{a}$ & $27,4 \mathrm{a}$ & $20,1 \mathrm{a}$ & $30,5 \mathrm{a}$ & $21,8 \mathrm{a}$ & $28,2 \mathrm{a}$ & $19,4 \mathrm{a}$ & $37,0 \mathrm{a}$ \\
\hline Mi & $20,4 a b^{2}$ & $22,5 \mathrm{~b}$ & $12,4 \mathrm{a}$ & $23,5 \mathrm{ab}$ & $18,4 \mathrm{a}$ & $38,6 \mathrm{a}$ & $19,0 \mathrm{a}$ & $31,0 \mathrm{a}$ & $20,5 \mathrm{a}$ & $30,3 \mathrm{a}$ \\
\hline $\mathrm{K}_{5}$ & $17,0 \mathrm{~b}^{3}$ & $21,7 b^{3}$ & $12,7 \mathrm{a}$ & $19,0 \mathrm{~b}$ & $15,8 \mathrm{a}$ & $20,7 \mathrm{~b}$ & $18,7 \mathrm{a}$ & $29,3 \mathrm{a}$ & $19,7 \mathrm{a}$ & $31,0 \mathrm{a}$ \\
\hline $\mathrm{P}>\mathrm{F}$ & 0,0046 & 0,0123 & 0,2551 & 0,0499 & 0,0732 & 0,0002 & 0,0411 & 0,7603 & 0,8533 & 0,2969 \\
\hline
\end{tabular}

${ }^{\mathrm{I}}$ Médias seguidas de mesma letra na coluna não diferem entre si pelo teste de Tukey a $5 \%$ de probabilidade. ${ }^{2}$ Médias de 8 repetições. 


\section{CONCLUSÕES}

Nas condições dos experimentos realizados, foi possível concluir que:

- o isolado $\mathrm{M}_{2}$ de Pratylenchus coffeae é parasito pouco agressivo do cafeeiro arábico, sendo potencialmente importante apenas quando ataca plantas muito novas (=plântulas);

- o isolado $\mathrm{K}_{5}$ de $P$. coffeae é muito agressivo ao cafeeiro arábico causando severa redução no crescimento de plantas de diferentes idades;

- há genótipos de Coffea canephora resistentes ao isolado $\mathrm{K}_{5}$ de Pratylenchus coffeae, que poderão vir a ser utilizados em programas de melhoramento genético visando ao controle desse nematóide. 


\section{REFERÊNCIAS BIBLIOGRÁFICAS}

BADEL, R. E.; AYALA, A. Chemical control of coffee nematodes in seedbeds in Puerto Rico. Journal of Agriculture of University of Puerto Rico. v. 64, n. 4, p. $474-481,1980$.

BONETTI, J.I.S.; FERRAZ, S. Modificação do método de Hussey \& Barker para extração de ovos de Meloidogyne exigua em raízes de cafeeiro. Fitopatologia Brasileira, v. 6, n. 3, p. 553, 1981.

CAMPOS, H. Estatística Experimental Não-paramétrica. Piracicaba: Departamento de Matemática e Estatística/ ESALQ, 1983. 211p.

CAMPOS, V. P.; SIVAPALAN, P.; GNANAPRAGASAM, N. C. Nematode parasites of coffee, cocoa and tea. In: LUC, M.; SIKORA, R.; BRIDGE, J. (Ed.).Plant parasitic nematodes in subtropical and tropical agriculture. Wallingford: $C A B$ Internacional, 1990. p. 387-430.

CARNEIRO, R.G. Reação de progênies de café Icatú a Meloidogyne incognita raça 2, em cond ições de campo. Nematologia Brasileira, v. 19, p. 53-59, 1995.

COOLEN, W. A.; D'HERDE, C. J. A method for the quantitative extraction of nematodes from plant tissue. Ghent, Belgium: State Nematology and Entomology Research Station, 1972. 77p. 
COSTA, W. M.; GONÇALVES, W; FAZUOLI, L. C. Produção do café 'Mundo Novo' em porta-enxertos de Coffea canephora em área infestada com Meloidogyne incognita raça 1. Nematologia Brasileira, v. 15, p. 43-50, 1991.

DUNCAN, L. W.; INSERRA, R. N.; THOMAS, S. K.; DUNN, D.; MUSTIKA, I; FRISSE, L. M.; MENDES, M. L.; MORRIS, K.; KAPLAN, D. T. Molecular and morphological analyses of isolates of Pratylenchus coffeae and closely related species. Nematropica, v.29, p.61-81,1999.

DUTRA, M. R. Nematóides avançam no café. Grande Culturas Cultivar, v. 5, n. 51, p.18-21, 2003.

FAZUOLI, L.C. Genética e melhoramento do cafeeiro. In: RENA,A.B.; MALAVOLTA,E.; ROCHA,M.; YAMADA,T. (Ed). Cultura do cafeeiro - fatores que afetam a produtividade. Piracicaba: Associação Brasileira para Pesquisa do Potássio e do Fosfato, 1986. p 87-113.

FAZUOLI, L.C.; COSTA, W.M.; FERNANDES, J.A.R. Variabilidade na resistência de linhagens de Coffea canephora em relação a uma população do nematóide Meloidogyne incognita em condições de campo. In: CONGRESSO BRASILEIRO DE PESQUISAS CAFEEIRAS, 10., Poços de Caldas, MG, 1983. Anais. Poços de Calda: CBPC, 1983, p.115-117.

GONÇALVES, W. Reações de cafeeiros (Coffea spp.) a Meloidogyne exígua Goeldi, 1887 e a diferentes populações de Meloidogyne incognita (Kofoid \& White, 1919) Chitwood, 1949. Jaboticabal, 1993. p.110. Tese (Doutorado) - Universidade Estadual Paulista "Júlio de Mesquita F." 
GONÇALVES, W.; FERRAZ, L. C. C. B. Resistência do cafeeiro a nematóides. IITestes de progênies e híbridos para Meloidogyne incognita raça 3. Nematologia Brasileira, v. 11, p.125-142, 1987.

GONÇALVES, W.; RAMOS, L.C.S.; FERNANDES, J.A.R.; KASAI, F.S. Avaliação da resistência de dois cultivares de Coffea canephora a Meloidogyne incognita raça 2. Nematologia Brasileira, v. 14, p. 45-53, 1990.

GONÇALVES, W. FERRAZ, L.C.C.B., LIMA, M.M.A.de; SILVAROLLA, M.B. Reações de cafeeiros às raças 1,2 e 3 de Meloidogyne incognita. Summa Phytopathologica, v. 22, n. 2, p.172-177. 1996.

INOMOTO, M. M.; OLIVEIRA, C. M.G.; MAZZAFERA, P. ; GONÇALVES, W. Effects of Pratylenchus brachyurus and P. coffeae on seedlings of Coffea arabica. Journal of Nematology, v. 30, p. 362-367, 1998.

INSERRA, R.N.; DUNCAN, L.W.; TROCCOLI, A.; DUNN, D.; SANTOS, J. M.; KAPLAN, D. ; VOVLAS, N. Pratylrnchus jaehni sp. n. from citrus in Brazil and its relationships with $P$. coffeae e $P$. loosi (Nematoda: Pratylenchidae). Nematology, v. 37, n. 7 , p. $653-665,2002$.

JENKINS, W.R. A rapid centrifugalflotation technique for separating nematodes from soil. Plant Disease Reporter, v. 48, p. 69, 1964.

KUBO, R. K.; INOMOTO, M. M.; OLIVEIRA, C. M. G.; ANTEDOMÊNICO, S. R.; MONTEIRO, A. M. Nematóides associados a cafeeiros do Estado de São Paulo. In: CONGRESSO BRASILEIRO DE NEMATOLOGIA, 23., Marília, 2001. Anais. Garça: Sociedade Brasileira de Nematologia, 2001. p.91. 
KUBO, R. K., SIlVA, R. A., TOMAZINI, M. D., OlIVEIRA, C. M. G., MAZZAFERA, P. ; INOMOTO, M. M. Patogenicidade de Pratylenchus coffeae em plântulas de cafeeiro cv. Mundo Novo. Fitopatologia Brasileira, v. 28, n.1, p. 41-48, 2003.

KUMAR, A. C.; SAMUEL, S. D. Nematodes attacking coffee and their management - a review. Journal of Coffee Research, v.20, n.1, p. 1-27, 1990.

LORDELLO, R. R. A.; LORDELLO A. I. L.; PPEREIRA, L.C.E. Recuperação de cafeeiros parasitados por Meloidogyne incognita raça 1. Nematologia Brasileira, v.11, p. 15, 1987.

MALUF, M.P.; GUERREIRO FILHO, O.; FAZUOLI, L.C. Biotecnologia: aporte tecnológico ao melhoramento do cafeeiro no IAC. O Agronômico, v. 53, n. 2, p. 5-7, 2001.

MATIELLO, J.B.; BARROS, U.V. Observações preliminares sobre o desenvolvimento de cafeeiros Catuaí (Coffea arabica) e Conillon (C. canephora) em duas regiões com diferentes diferenciais de altitudes em Minas Gerais. In: CONGRESSO BRASILEIRO DE PESQUISAS CAFEEIRAS, 24., Poços de Caldas, MG, 1998. Ana is, Poços de Caldas: CBPC, 1998. p. 54.

MONTEIRO, A. R.; LORDELLO, L. G. E. Encontro do nematóide Pratylenchus coffeae atacando cafeeiro em São Paulo. Revista de Agricultura, v. 49, n. 1, p. 164, 1974.

MORERA, N.G.; LÓPEZ Ch, R. Repuesta de seia líneas experimentales de Coffea spp. a la inoculation con Meloidogyne exigua. Nematropica, v. 17, n. 2, p. 103-109, 1987. 
MOURA, R.M.; PEDROSA, E.M.E.; PRADO,M.D.C. Incidência de Pratylenchus coffeae causando severa nematose em cafeeiros no nordeste. Fitopatologia Braileira, v. 27 , n. 6 , p. $649,2002$.

OOSTENBRINK, M. Major characteristics of the relation between nematodes and plants. Mededelingen Van De landbouwhogeschool Te Wageningen v.66, n.4, p.1-46, 1966.

REBEL, E. K.; FAUZOLI, L. C. Fontes de resistência de cafeeiros ao nematóide $M$. incognita. In: CONGRESSO BRASILEIRO DE PESQUISAS CAFEEIRAS, 6., Ribeirão Preto, SP, 1978. Anais, Ribeirão Preto: CBPC. 1978a. p.187-191.

RIEDEL, R.M., FOSTER, J.G.; MAI, W.F. A simplified medium for monoxenic culture of Pratylenchus penetrans and Ditylenchus dipsaci. Journal of Nematology, v. 5, p. 71-71, 1973.

SCHIEBER, E.; GRULLON, L. El problema de nematodos que atacam al café (Coffea arabica) en la Republica Dominicana. Turrialba, v. 19, n. 4, p. 513-517, 1969.

SILVA, R. A.; INOMOTO, M.M. Host-range characterization of two Pratylenchus coffeae isolates from Brazil. Journal of Nematology, v. 34, n. 2, p. 135-139, 2002.

SIMON, M.T. Melhoramento genético em café. In: ENCONTRO SOBRE PRODUÇÃO DE CAFÉ COM QUALIDADE, 1.,Viçosa. 1999 Anais. Viçosa: Suprema Gráfica e Editora, 1999. 259p.

SOUTHEY, J.F. Laboratory methods for work with plant and soil nematodes. London. Her Majesty’s Stationery Office, 1986. 265 p. 
TAYLOR, A. L.; SASSER, J. N. Biology, Identification and Control of Root-knot Nematodes (Meloidogyne species). Raleigh, North Carolina State Univ: Graphics, 1978. 111p.

VILLAIN, L.; ANZUETO, F.; SARAH, J. L. Resistance to root-lesion nematodos in Coffea canephora. Nematology, v. 4, n. 2, p. 186, 2002. (Resumos)

VILLAIN, L.; MOLINA, A.; SIERRA, S.; DECAZY, B. ; SARAH, J. L. Effect of grafting and nematicide treatments on damage by root-lesion (Pratylenchus spp.) to Coffea arabica L. in Guatemala. Nematropica, v. 30, n.1, p. 87-100, 2000.

VOLPATO, A.R.; OTOBONI, C.E.M.; OTOBONI, J.A.M., CORRÊA, L.E.A.; SARAIVA, R.F. Eficácia dos produtos Casudafós, Carbofuram e Carbosulfam no controle de Meloidogyne exigua e M. coffeicola no cafeeiro. In: CONGRESSO BRASILEIRO DE NEMATO LOGIA, 23., Marília, 2001. Anais. Garça: Sociedade Brasileira de Nematologia, 2001. p.92. 